\title{
SARS-CoV-2 vaccination in cardiothoracic organ transplant recipients: effective strategies wanted
}

\author{
Sebastian Ewen ${ }^{1}$ (1) $\cdot$ Frank Neumann ${ }^{2} \cdot \mathrm{Jörg}^{\mathrm{T}}$. Bittenbring ${ }^{2} \cdot$ Wolfgang von Scheidt $^{3} \cdot$ Michael Böhm $^{1}$
}

Received: 17 May 2021 / Accepted: 18 May 2021 / Published online: 9 July 2021

(c) The Author(s) 2021

Keywords SARS-CoV-2 Vaccination - Cardiothoracic organ transplant recipients

Since end of 2019, the severe acute respiratory syndrome coronavirus 2 (SARS-CoV-2) has spread from Wuhan, China to the rest of the world, leading to more than 160 million confirmed cases of coronavirus disease 2019 (COVID-19) with more than 3.3 million deaths worldwide [1]. COVID19 results in a spectrum of clinical manifestations ranging from asymptomatic to critical illness including acute respiratory distress syndrome (ARDS) and multiorgan failure, which are associated with high morbidity and mortality. Factors that increase risk for an adverse disease course include older age and the presence of comorbidities such as diabetes, hypertension, chronic kidney disease, morbid obesity, coronary heart disease, and chronic lung disease [2]. Solid organ transplant (SOT) patients are considered to be at high risk for complications from COVID-19 because of the high prevalence of the comorbidities that have been established as risk factors for severe disease, as well as a higher risk of infection due to their immunosuppressed status [3,4]. Current data on the clinical course of COVID-19 in immunocompromised patients are limited.

Sebastian Ewen

sebastian.ewen@uks.eu

1 Klinik für Innere Medizin III, Kardiologie, Angiologie und Internistische Intensivmedizin, Universitätsklinikum des Saarlandes und Medizinische Fakultät der Universität des Saarlandes, Kirrberger Str. 100, 66421 Homburg, Saar, Deutschland

2 Klinik für Innere Medizin I, Onkologie, Hämatologie, Klinische Immunologie und Rheumatologie, Universitätsklinikum des Saarlandes und Medizinische Fakultät der Universität des Saarlandes, Homburg, Saar, Deutschland

3 I. Medizinische Klinik, Kardiologie, Pneumologie, Internistische Intensivmedizin, Endokrinologie, Universitätsklinikum Augsburg, Augsburg, Deutschland
Vaccination against COVID-19 may be an effective intervention in fighting the pandemic. Several SARS-CoV-2 vaccines have been approved for administration in various countries and are available to select populations based on local recommendations and regulations. Current efficacy data from randomized clinical trials in immunocompetent recipients are variable as noted in Table 1 , but thus far consistently demonstrate close to $100 \%$ protection against severe COVID-19-related intensive care hospitalization or death [5]. Observational "real-world" findings from Israel, including 596,618 vaccinated persons matched to unvaccinated controls, demonstrated an $87 \%$ reduction in COVID-19-related hospitalization following administration of two doses of the Pfizer-BioNTech vaccine [6]. Safety and efficacy data for SARS-CoV-2 vaccines in transplant recipients are limited thus far, as transplant recipients were not included in the already published randomized vaccine trials [5]. However, guidelines regarding COVID-19 vaccination in patients with thoracic transplantation have been released by the International Society for Heart and Lung Transplantation (ISHLT) and the American Society for Transplantation (AST) in a combined statement [7], as well as by the European Society of Cardiology (ESC) [8], unequivocally recommending vaccination at least 1 month after transplant surgery.

In this issue of the Journal, Schramm and colleagues [9] report on a prospective cohort study of the immune response after administration of the BNT162b2 vaccine in 50 cardiothoracic (heart $(n=42)$, lung $(n=7)$ or heart-lung $(n=1))$ transplant recipients from 5 German transplant centers 10-36 months after transplantation, compared to 50 healthy staff members similarly immunized with the same messenger RNA (mRNA) vaccine. Antibody titers, functional inhibitory capacity of neutralizing antibodies, and T-cell response (interferon- $\gamma$ release) were measured via three separate tests. Forty-six $(92 \%)$ of the transplant recipients did not show any humoral or T-cell response 21 days after completion 
Table 1 SARS-CoV-2 vaccinations available globally, as of May 10, 2021 (Adapted from [5])

\begin{tabular}{llll}
\hline Manufacturer & Type & $\begin{array}{l}\text { Vaccine efficacy reported in } \\
\text { clinical trials }(\%)\end{array}$ & $\begin{array}{l}\text { Prevention of severe disease } \\
\text { leading to death in clinical trials } \\
(\%)\end{array}$ \\
\hline Pfizer/BioNTech & mRNA & 95 & 100 \\
Moderna & mRNA & 94.5 & 100 \\
Sputnik V & Ad26/Ad5 & 91.4 & 100 \\
AstraZeneca & ChAdOx1 & $60-85$ & 100 \\
Johnson \& Johnson & Ad26 & $57-72$ & 100 \\
Cansino & Ad5 & 66 & 100 \\
Sinopharm & Inactivated & $79.6-86$ & 100 \\
Sinovac & Inactivated & 50.1 & 100 \\
Novavax & Protein & $86-96$ & 100 \\
\hline
\end{tabular}

of the second vaccine dose [9]. In contrast, humoral vaccination success (IgG antibodies and neutralizing antibodies) in healthy controls was seen in 49 subjects (98\%) after the first vaccine dose, and in $100 \%$ after the second vaccine dose [9]. Additionally, healthy controls developed a significantly higher positive T-cell response (interferon- $\gamma$ release) compared to transplant recipients (80\% vs 16\%) [9]. It is concluded that the BNT162b2 vaccine does not confer vaccination success against SARS-CoV-2 in the vast majority of cardiothoracic transplant recipients.

The presented data indicate that patients receiving immunosuppression are less likely to respond to mRNA-based SARS-CoV-2 vaccination compared to immunocompetent participants included in SARS-CoV-2 vaccine trials [10]. Although data regarding the new vaccine technology using mRNA in transplant recipients are scarce, it is known that patients who underwent a transplant do not develop optimal immune responses following many vaccines (e.g., influenza vaccination) [11]. The reasons for this are multifactorial but may include (i) the time since transplantation, (ii) the amount and nature of immunosuppression and (iii) the occurrence of concomitant allograft rejection that interferes with the production of the requisite neutralizing antibodies [12]. A study of COVID-19 vaccine responses among kidney transplant recipients indicated that all 25 members of the control group developed a positive humoral immune response to the viral spike proteins, compared with only $37.5 \%$ out of 136 transplant recipients who had a positive serology test [13]. A prospective cohort study including 658 SOT recipients (97 heart recipients and 71 patients who underwent lung transplantation) across the US showed that only a low proportion (15\%) of transplant patients mounted a positive antibody response after the first vaccine dose, which increased to $54 \%$ of transplant recipients after dose 2 [12]. Although this study demonstrates an increase in antibody responses in transplant patients after the second vaccine dose compared with the first, data indicates, in line with the investigation presented herein, that a substantial proportion of transplant patients are likely to remain at risk for COVID19 despite being administered a full dose of an mRNAbased vaccine. Currently, there are not enough comparative studies in transplant patients evaluating the differences in immune response to the various COVID-19 vaccine types already developed. Therefore, further studies are urgently needed to address interventions including different types of vaccination, additional booster doses, optimization of $\mathrm{t}$-cell responses of current vaccines or immunosuppression modulation to improve vaccine responses in this high-risk population. Larger, multicenter studies also need to be performed to disentangle the group of non-responders from the group who would benefit from traditional dosing. It remains unclear whether a lack of antibody response after COVID-19 vaccination is associated with a higher risk of infection or a worse course of the disease after infection.

Although the exact impact of chronic immunosuppression on COVID-19 outcomes remains ambiguous as of today, its role seems to be highly relevant as host inflammatory responses appear to constitute an important cause of associated organ injury [3]. As the manifestations of severe COVID-19, including ARDS and organ dysfunction, may be propagated by a proinflammatory state due to cytokine release syndrome, immunosuppressive therapy could potentially mitigate some of these effects and thereby help prevent severe complications in SOT patients [3]. One multicenter study comparing ICU COVID-19-positive SOT recipients with matched controls found no difference in rates of ARDS or death between groups [3]. Although some smaller singlecenter studies have shown excess mortality in patients who underwent a transplant, many were conducted in regions with overwhelmed hospital systems at the time of patient presentation [14]. In the case of vulnerable, immunocompromised patients with a severe disease course, passive immunization against COVID-19 using convalescent sera or engineered antibody cocktails might be an option, barring circulating resistant variants. However, in 228 randomized hospitalized patients with severe COVID-19 pneumonia, no 
significant differences in clinical status or mortality were detected after 30 days between patients treated with convalescent plasma and those who received placebo [15].

COVID-19 will likely circulate for many years, if not indefinitely. Based on the presented findings, routinely testing for antibody response (or even T-cell response) in transplant recipients following COVID-19 vaccination should be strongly recommended to prevent false security in this high-risk group. All transplant recipients have to be counseled to continue practicing protective measures including mask use, hand hygiene, and social distancing even if they are vaccinated. As with other very contagious viral pathogens such as measles, real protection of the immunocompromised could only be possible by vaccinating relatives and all fellow human beings to achieve "herd immunity". The ultimate question that remains is whether it should continue to be recommended that all patients be vaccinated against COVID-19 after heart or lung transplants-as of today, the answer is YES! But more effective, yet unclear strategies are urgently needed.

Funding Open Access funding enabled and organized by Projekt DEAL.

\section{Declarations}

Conflict of interest None of the authors declares a specific conflict of interest due to the contend of this editorial.

Open Access This article is licensed under a Creative Commons Attribution 4.0 International License, which permits use, sharing, adaptation, distribution and reproduction in any medium or format, as long as you give appropriate credit to the original author(s) and the source, provide a link to the Creative Commons licence, and indicate if changes were made. The images or other third party material in this article are included in the article's Creative Commons licence, unless indicated otherwise in a credit line to the material. If material is not included in the article's Creative Commons licence and your intended use is not permitted by statutory regulation or exceeds the permitted use, you will need to obtain permission directly from the copyright holder. To view a copy of this licence, visit http://creativecommons.org/licenses/by/4.0/.

\section{References}

1. Johns Hopkins University of Medicine, Coronavirus Resource Center, vol 15, p 38. https://coronavirus.jhu.edu/map.html. Accessed 13 May 2021
2. Atri D, Siddiqi HK, Lang JP, Nauffal V, Morrow DA, Bohula EA (2020) COVID-19 for the cardiologist: basic virology, epidemiology, cardiac manifestations, and potential therapeutic strategies. JACC Basic Transl Sci 5(5):518-536

3. Molnar MZ, Bhalla A, Azhar A, Tsujita M, Talwar M, Balaraman V, Sodhi A, Kadaria D et al (2020) Outcomes of critically ill solid organ transplant patients with COVID-19 in the United States. Am J Transplant 20(11):3061-3071

4. Weis M, von Scheidt W (1997) Cardiac allograft vasculopathy: a review. Circulation 96(6):2069-2077

5. Kim JH, Marks F, Clemens JD (2021) Looking beyond COVID-19 vaccine phase 3 trials. Nat Med 27(2):205-211

6. Dagan N, Barda N, Kepten E, Miron O, Perchik S, Katz MA, Hernán MA, Lipsitch M et al (2021) BNT162b2 mRNA Covid-19 vaccine in a nationwide mass vaccination setting. $\mathrm{N}$ Engl J Med 384(15):1412-1423

7. The International Society for Heart and Lung Transplantation (2021) Statement on COVID-19 vaccination in solid organ transplant recipients, vol 15, p 44. https://ishlt.org/covid-19-infor mation. Accessed 13 May 2021

8. COVID-19 vaccine information for heart patients, vol 15, $\mathrm{p} 48$. https://www.escardio.org/Education/COVID-19-and-Cardiology/ covid-19-and-vaccinations. Accessed 13 May 2021

9. Schramm R, Costard-Jäckle A, Rivinius R, Fischer B, Müller B, Haneya A, Provaznik Z, Knabbe C et al (2021) Poor humoral and T-cell response to two-dose SARS-CoV-2 messenger RNA vaccine BNT162b2 in cardiothoracic transplant recipients. Clin Res Cardiol. https://doi.org/10.1007/s00392-021-01880-5

10. Walsh EE, Frenck RW, Falsey AR, Kitchin N, Absalon J, Gurtman A, Lockhart S, Neuzil K et al (2020) Safety and immunogenicity of two RNA-based Covid-19 vaccine candidates. N Engl J Med 383(25):2439-2450

11. Dengler TJ, Strnad N, Bühring I, Zimmermann R, Girgsdies O, Kubler WE, Zielen S (1998) Differential immune response to influenza and pneumococcal vaccination in immunosuppressed patients after heart transplantation. Transplantation 66(10):1340-1347

12. Boyarsky BJ, Werbel WA, Avery RK, Tobian AAR, Massie AB, Segev DL, Garonzik-Wang JM (2021) Antibody response to 2-dose SARS-CoV-2 mRNA vaccine series in solid organ transplant recipients. JAMA. https://doi.org/10.1001/jama.2021.7489 (published online)

13. Grupper A, Rabinowich L, Schwartz D, Schwartz IF, Ben-Yehoyada M, Shashar M, Katchman E, Halperin T et al (2021) Reduced humoral response to mRNA SARS-CoV-2 BNT162b2 vaccine in kidney transplant recipients without prior exposure to the virus. Am J Transplant. https://doi.org/10.1111/ajt.16615 (published online)

14. Pereira MR, Mohan S, Cohen DJ, Husain SA, Dube GK, Ratner LE, Arcasoy S, Aversa MM et al (2020) COVID-19 in solid organ transplant recipients: initial report from the US epicenter. Am J Transplant 20(7):1800-1808

15. Simonovich VA, Pratx LDB, Scibona P, Beruto MV, Vallone MG, Vázquez C, Savoy N, Giunta DH et al (2021) A randomized trial of convalescent plasma in Covid-19 severe pneumonia. N Engl J Med 384(7):619-629 